\title{
Antiepileptic Effects of 20-Hydroxyecdysone on Convulsive Seizures in Spontaneously Epileptic Rats
}

\author{
Ryosuke Hanaya ${ }^{1}$, Masashi Sasa ${ }^{2, *}$, Kumatoshi Ishihara ${ }^{2}$, Tomohide Akimitsu' ${ }^{1}$, Koji Iida $^{1}$, Taku Amano $^{2}$, \\ Tadao Serikawa ${ }^{3}$, Kazunori Arita ${ }^{1}$ and Kaoru Kurisu ${ }^{1}$ \\ Departments of ${ }^{1}$ Neurosurgery and ${ }^{2}$ Pharmacology, Hiroshima University School of Medicine, Hiroshima 734, Japan \\ ${ }^{3}$ Institute of Laboratory Animals, Faculty of Medicine, Kyoto University, Kyoto 606, Japan \\ Received March 28, $1997 \quad$ Accepted June 24, 1997
}

\begin{abstract}
We examined the effect of 20-hydroxyecdysone (20-HE), a neurosteroid found in insects that is involved in their developmental process, on both tonic convulsion and absence-like seizure in spontaneously epileptic rat (SER). When $20-\mathrm{HE}$ was given orally to SER at $25-200 \mathrm{mg} / \mathrm{kg}$, significant decreases of the tonic convulsion were observed with 100 and $200 \mathrm{mg} / \mathrm{kg}$. Pretreatment of the animal with bicuculline (1 $\mathrm{mg} / \mathrm{kg}$, i.p.) antagonized the inhibitory effects of 20-HE. However, absence-like seizures were not affected by $20-\mathrm{HE}$. These findings indicate that 20 -HE produces antiepileptic effects on tonic convulsion by acting on the modulatory site of $\mathrm{GABA}_{\mathrm{A}}$ receptors.
\end{abstract}

Keywords: Spontaneously epileptic rat (SER), 20-Hydroxyecdysone, Antiepileptic effect

20-Hydroxyecdysone (20-HE) (Fig. 1A) is a neurosteroid found in insects that plays a major role in the developmental process (1). This neurosteroid acts on ecdysone receptors (EcR) of Drosophila (2), and Drosophila EcR has effects on cultured mammalian cells as an ecdysteroid-dependent transcription factor (3). Neurosteroids such as progesterone and its metabolites, including $5 \alpha$-pregnan-3 $\alpha$-ol-20-one ( $3 \alpha$-OH-DHP), have $\mathrm{GABA}_{\mathrm{A}}$-receptor agonistic activities and antiepileptic effects $(4,5)$. However, other neurosteroids including pregnenolone sulfate and dehydroepiandrosterone sulfate show antagonistic activities for $\operatorname{GABA}(6,7)$. We have previously reported that $20-\mathrm{HE}$ potentiates $\mathrm{GABA}_{\mathrm{A}}$ receptor-mediated currents in cultured cortical neurons of rats (8). Therefore, 20-HE is expected to inhibit the epileptic seizures.

The spontaneously epileptic rat (SER) is a double mutant $(\mathrm{zi} / \mathrm{zi}, \mathrm{tm} / \mathrm{tm})$ obtained originally by mating a heterozygote tremor rat $(\mathrm{tm} /+)$, a mutant found in the inbred colony of Kyoto-Wistar rats (9), with homozygote zitter rats found in a Sprague-Dawley colony (10). After 8 weeks of age, the SER spontaneously shows tonic convulsions with low voltage fast waves and absence-like seizures characterized by sudden behavioral changes such as immobility and staring with simultaneous appearance of

\footnotetext{
* To whom correspondence should be addressed.
}

paroxysms of $5-7 \mathrm{~Hz}$ spike-wave complexes in cortical and hippocampal EEG, although mild stimuli such as a hand clap and blow on the face easily induce convulsions $(11,12)$. This animal is useful for the evaluation of antiepileptics because the antiepileptic profile of antiepileptic drugs for tonic convulsion and absence-like seizures in SER is in line with those of human grand mal and petit mal epilepsy, respectively (12).

Thus, we examined the antiepileptic effects of 20-HE using SER with chronically implanted electrodes for recording cortical and hippocampal EEG.

Sixteen SER of each sex weighing $150-220 \mathrm{~g}$ and aged 10-16 weeks of age were used. All animals were kept in cages in a room maintained at $23 \pm 2{ }^{\circ} \mathrm{C}$ and $55 \pm 5 \%$ humidity. They were provided with standard rat chow (MF; Oriental Yeast, Tokyo) and tap water ad libitum.

Under sodium pentobarbital anesthesia $(30 \mathrm{mg} / \mathrm{kg}$, i.p.), a silver-tipped electrode was chronically implanted in the left frontal cortex, and an enamel-coated stainlesssteel electrode was stereotaxically placed in the left hippocampus ( $\mathrm{P}, 4.0 ; \mathrm{L}, 2.0 ; \mathrm{H}, 2.0 \mathrm{~mm}$ from bregma), according to the coordinates of the brain atlas of Paxinos and Watson (13). A reference electrode was fixed on the frontal cranium. After a 7-day recovery period, each animal was placed in a sound-proof box $(40 \times 40 \times 40 \mathrm{~cm})$ with a small window $(11 \times 6 \mathrm{~cm})$ to allow behavioral observation. After a 30-min habituation to the circum- 
(A)

(B)

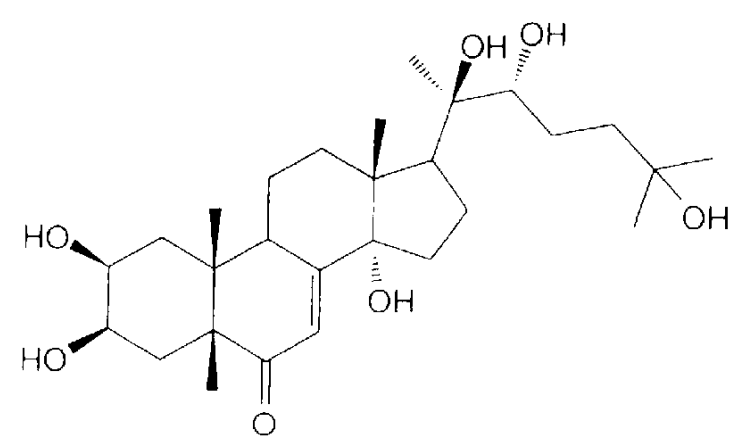

\section{Control}
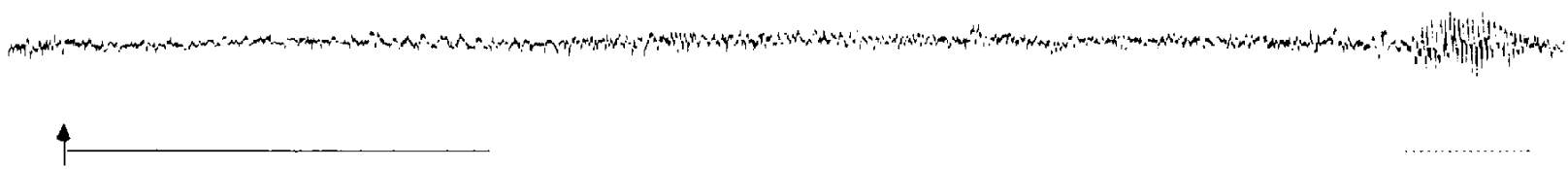

S Tonic convulsion

Absence scizure

20-hydroxyecdysone, $200 \mathrm{mg} / \mathrm{kg}$, p.o., $50 \mathrm{~min}$

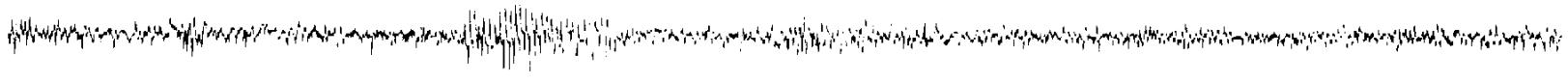

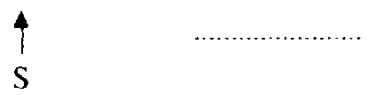

1
$10 \mathrm{sec} \quad 200 \mu \mathrm{V}$

Fig. 1. Structure of 20-hydroxyecdysone (20-HE) (A) and the inhibitory effect of 20-HE on tonic convulsion characterized by low-voltage fast waves (B). The arrow indicates blowing stimulation on the back of the animal. Solid and dotted lines under the EEG trace show the period of tonic convulsion and absence-like seizures, respectively. After administration of 20-HE, blowing stimulation failed to induce tonic convulsion.

stances, EEG was recorded for $30 \mathrm{~min}$ (as control) before administrations of $20-\mathrm{HE}$, with a pen-tracing polygraph (RM 6200; Nihon Kohden, Tokyo) and stored on personal computers (Macintosh SE 30; Apple Computer, Inc., Cupertino, CA, USA). The post-drug EEG was continuously recorded for $120 \mathrm{~min}$. Changes in EEG during the absence-like seizure consistently correlated with the respective abnormal changes of the behavior, as described previously $(11,12)$. When $5-7 \mathrm{~Hz}$ spike-wave complexes in cortical and hippocampal EEG lasted for more than $1 \mathrm{sec}$, the animal was considered to show an absence-like seizure. When the time interval between two independent $5-7 \mathrm{~Hz}$ spike-wave complexes was less than $1 \mathrm{sec}$, the two events were regarded as a single seizure. Animals were given blowing stimuli on the back by the researcher every 5 min during the entire recording period to induce arousal and consistent tonic seizures. EEG recordings were always made between 9:00 and 19:00 hr.
20-HE, obtained from plants and kindly provided by Daicel Chemical Ind. (Tokyo), was administered p.o. as a solution containing $100 \mathrm{mg} / \mathrm{ml}$ in physiological saline at the doses of $25,50,100$ and $200 \mathrm{mg} / \mathrm{kg}$. Bicuculline (Sigma Chemical Co., St. Louis, MO, USA), an antagonist of $\mathrm{GABA}_{\mathrm{A}}$ receptors, was injected i.p. once at a dose of $1 \mathrm{mg} / \mathrm{kg}, 15 \mathrm{~min}$ before administration of 20-HE. Each animal was administered a single dose of $20-\mathrm{HE}$ on the day of the experiment. When the same animal was exposed to repeated drug conditions, the wash-out period was not less than 1 week. Seizure duration and frequency were measured, and the cumulative duration of seizures at 15 -min intervals was calculated. Statistical significance of the differences between pre- and post-administration of 20 -HE $(100 \mathrm{mg} / \mathrm{kg})$ was determined by repeated analysis of variance (ANOVA). Differences of the total duration of tonic convulsion between saline- and 20-HE-treated groups and those between 20-HE- and bicuculline-treated 
groups were examined with one-way ANOVA followed by Dunnett's test and Bonferroni's/Dunn's test, respectively. Significant differences of absence seizures between pre- and post-20-HE treatment were determined by Kruskal-Walis' test. Prior to those tests, statistical differences of variances were tested by Bartlett's test.

All 16 SER showed tonic convulsion and absence seizures characterized by low voltage fast waves and $5-7 \mathrm{~Hz}$ spike-wave-like complexes in EEG, respectively. The mean frequencies of tonic convulsion and absence-like seizures were $2.66 \pm 0.10$ and $40.28 \pm 3.20$ times $/ 15 \mathrm{~min}$ (mean \pm S.E.M.), respectively. The duration of each seizure was $23.11 \pm 0.75$ and $2.54 \pm 0.05 \mathrm{sec}$, respectively. $20-\mathrm{HE}$ at doses up to $200 \mathrm{mg} / \mathrm{kg}$ did not affect the background EEG or the behavior of SER. However, time course analyses (repeated measure ANOVA) revealed that
$20-\mathrm{HE}$ at $100 \mathrm{mg} / \mathrm{kg}$ was effective in inhibiting the tonic conulsion ( $F=3.490, P=0.0082$ ) (Figs. $1 B$ and 2). In addition, multiple dose analyses (Dunnett's test) also revealed that $20-\mathrm{HE}$ at doses of 100 and $200 \mathrm{mg} / \mathrm{kg}$ significantly $(P<0.05)$ reduced cumulative durations and incidence frequencies of the tonic convulsions. The inhibitory effects of $200 \mathrm{mg} / \mathrm{kg}$ of $20-\mathrm{HE}$ lasted longer than those of $100 \mathrm{mg} / \mathrm{kg}$, persisting for more than $60 \mathrm{~min}$ (Fig. 3A). $20-\mathrm{HE}$ at the doses of 25 and $50 \mathrm{mg} / \mathrm{kg}$ did not significantly affect the tonic convulsion in SER. In contrast to the tonic convulsion, the absence-like seizures were not significantly affected by $20-\mathrm{HE}$ at doses of $25-200 \mathrm{mg} / \mathrm{kg}$ (Figs. 2 and 3A).

Bicuculline at the dose of $1 \mathrm{mg} / \mathrm{kg}$ alone did not affect the behavior, background EEG, or the duration and frequency of the tonic convulsion or absence-like seizures of

\section{Tonic convulsion}

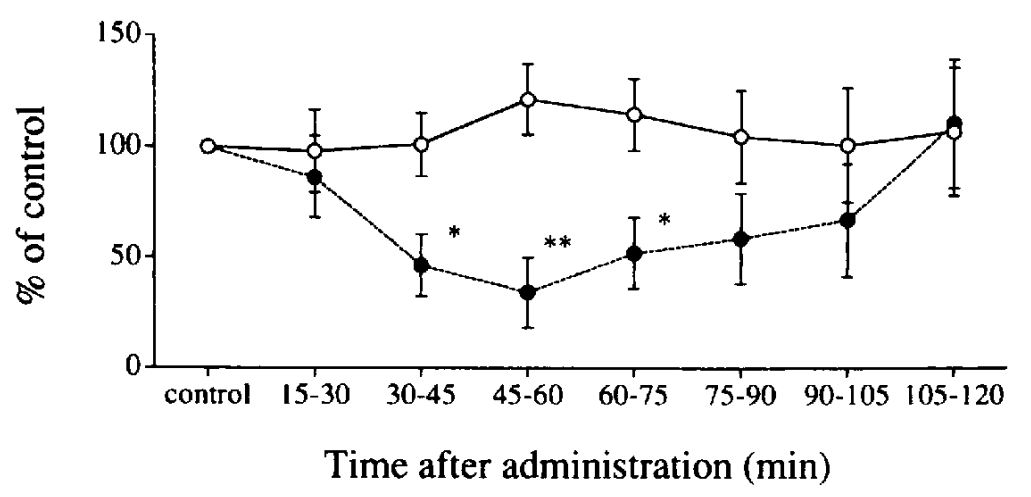

Absence seizure

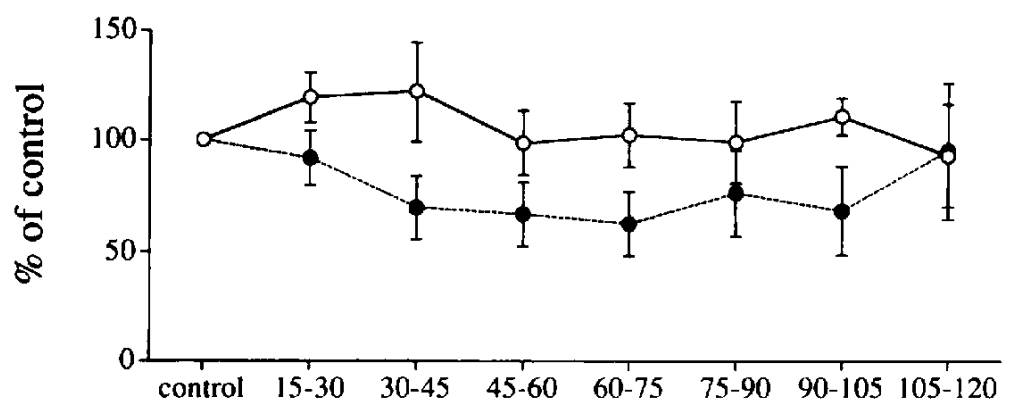

Time after administration (min)

Fig. 2. The effects of 20-hydroxyecdysone (20-HE) $(100 \mathrm{mg} / \mathrm{kg})$ on the total duration of both tonic convulsion and absencelike seizures. The percent of control was obtained by dividing each value after drug administration by that before administration. Each point and bar shows a mean and S.E.M., respectively. $\bigcirc$ and $O$ : physiological saline $(n=5)$ - and 20-HE ( $n=5)$ treated group, respectively. ${ }^{*} \mathrm{P}<0.05,{ }^{* *} \mathrm{P}<0.01$, as compared with the saline-treated group. 
SER. When bicuculline at a dose of $1 \mathrm{mg} / \mathrm{kg}$ was given to the animals $15 \mathrm{~min}$ before the administration of $20-\mathrm{HE}$ at a dose of $100 \mathrm{mg} / \mathrm{kg}$, the tonic convulsion was not in- hibited. Antagonizing effects of bicuculline against 20HE-induced inhibition of the seizures were observed in all 4 tested animals. The mean total duration of the tonic
(A)

\section{Tonic convulsion}

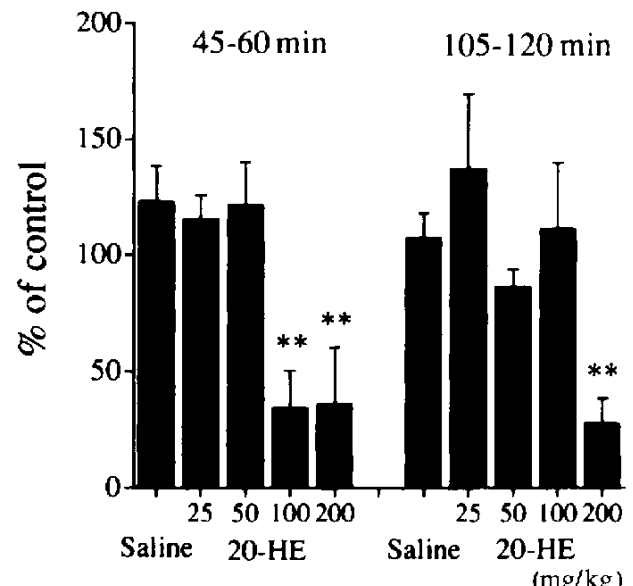

(B)

\section{Tonic convulsion}

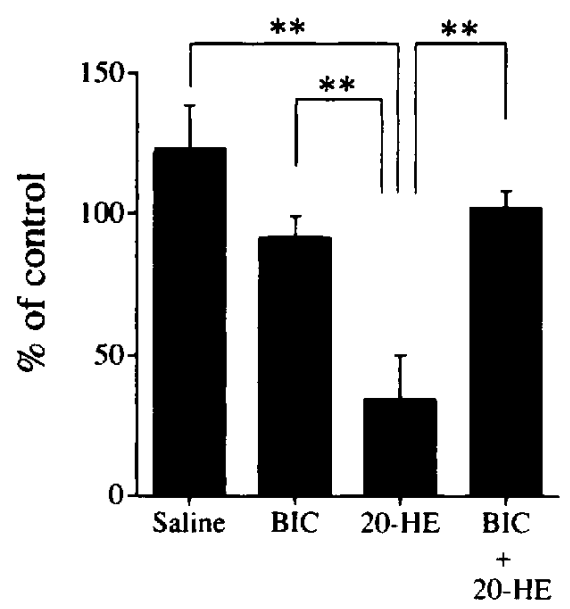

\section{Absence seizure}

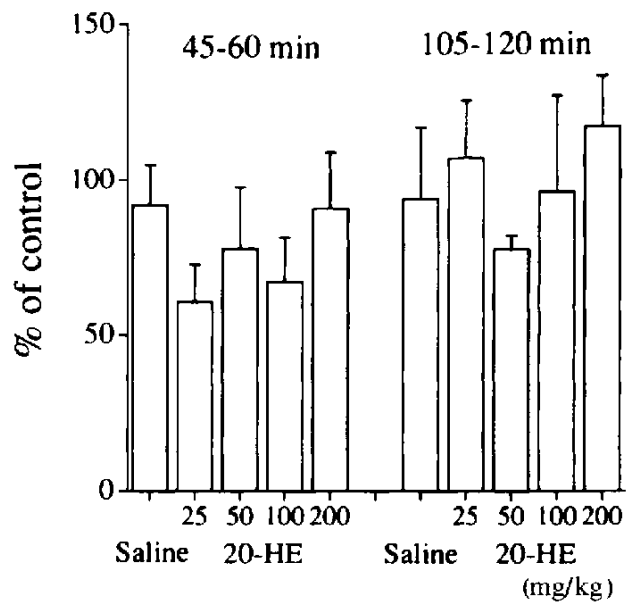

\section{Absence seizure}

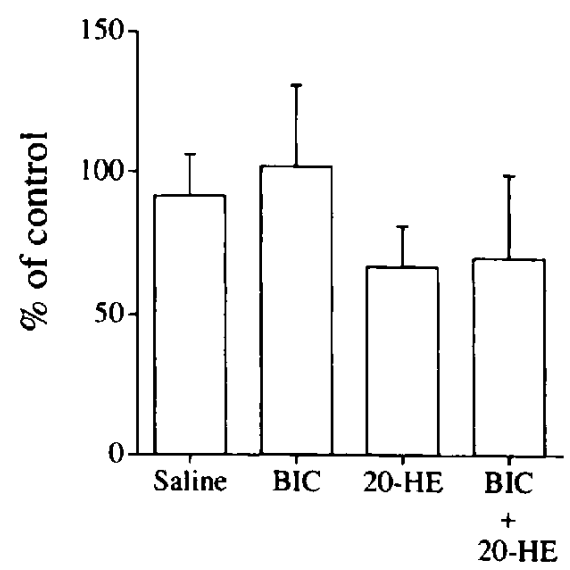

Fig. 3. The effcets of 20-hydroxyecdysone (20-HE; $25,50,100$ and $200 \mathrm{mg} / \mathrm{kg}, \mathrm{p} . \mathrm{o}$ ) on the epileptic seizures and antagonism by bicuculline (BIC) of 20-HE-induced inhibition of the seizures in SER. A: The effects of 20-HE at doses of $25,50,100$ and $200 \mathrm{mg} / \mathrm{kg}$ on the total duration of tonic convulsion and absence-like seizures. The total duration of the seizures (summation of duration of each seizure for $15 \mathrm{~min}$ ) was measured for $15 \mathrm{~min}$ before drug administration and 45-60 and $105-120 \mathrm{~min}$ after injection of the drug. Each value is a percentage of the values obtained for $15 \mathrm{~min}$ before drug administration. Each column and bar represents a mean and S.E.M. $(n=4-5)$, respectively. ${ }^{* *} \mathrm{P}<0.01$, as compared with the saline-treated group. B: Effects of bicuculline $(1 \mathrm{mg} / \mathrm{kg}, \mathrm{i} . \mathrm{p} ., \mathrm{n}=4)$ alone and $20-\mathrm{HE}(100 \mathrm{mg} / \mathrm{kg}, \mathrm{p} .0 ., \mathrm{n}=5)$ alone on tonic convulsion and absence-like seizures, as well as antagonism by BIC against 20-HE-induced inhibition of the seizures. The effect of BIC alone was examined 60-75 min after the injection. BIC was injected $15 \mathrm{~min}$ before the administration of 20 -HE. The effects of the combination of 20-HE with BIC were examined $45-60$ min after administration of 20-HE. Each column and bar represents a mean and S.E.M. $(\mathrm{n}=4-5)$, respectively. ${ }^{* *} \mathrm{P}<0.01$. 
convulsion for 15 min was reduced to $34.25 \pm 15.93 \%$ of the previous value with $20-\mathrm{HE}(100 \mathrm{mg} / \mathrm{kg})$ and recovered to $101.65 \pm 5.97 \%$ with 20 - $\mathrm{HE}(100 \mathrm{mg} / \mathrm{kg})$ in the animals pretreated with bicuculline $(1 \mathrm{mg} / \mathrm{kg})$. The multiple group analysis (Bonferroni's/Dunn's test) revealed that the antagonizing effect of bicuculline on 20-HE-induced inhibition was significant $(F=9.296, P=0.0012)$ (Fig. 3B).

Tonic convulsion in SER was dose-dependently inhibited by $20-\mathrm{HE}$, and this inhibitory effect was antagonized by bicuculline. Therefore, inhibition of the seizure by $20-\mathrm{HE}$ may be mediated by $\mathrm{GABA}_{\mathrm{A}}$ receptors. 20-HE may potentiate the inhibitory action of intrinsic GABA, thereby inhibiting the seizures, which is in line with the previous finding that 20-HE enhanced GABAinduced $\mathrm{Cl}^{-}$current in primary cultured cortical neurons (8). In such cultured neurons, 20-HE alone did not induce any current. Furthermore, the agonists that act on the modulatory sites of $\mathrm{GABA}_{\mathrm{A}}$ receptors such as benzodiazepines and barbiturates were effective in inhibiting the tonic convulsion in SER $(12,14)$.

However, unlike benzodiazepines or barbiturates, 20HE alone did not produce any behavioral changes such as sedation and sleep, or background EEG. The difference in the actions of 20-HE on the behavior from those of benzodiazepines and barbiturates may be due to the differences in the binding site of $20-\mathrm{HE}$ in $\mathrm{GABA}_{\mathrm{A}}$ receptors from the others.

In conclusion, 20-HE shows antiepileptic effects by enhancing the GABA actions in SER.

\section{Acknowledgments \\ We are grateful to Drs. Y. Yamaguchi and T. Matsumoto, Dicel Chemical Industries, for the gift of 20-hydroxyecdysone.}

\section{REFERENCES}

1 Koolman J: Ecdysteroid. Zoological Science 7, 563-580 (1990)

2 Koelle MR, Talbot WS, Segraves WA, Bender MT, Cherbas P and Hogness DS: The Drosophila EcR gene encodes an ecdysone receptor, a new member of the steroid receptor super- family. Cell 67, 59-77 (1991)

3 Christopherson KS, Mark MR, Bajaj V and Godowski PJ: Ecdysteroid-dependent regulation of genes in mammalian cells by a Drosophila ecdysone receptor and chimeric transactivators. Proc Natl Acad Sci USA 89, 6314-6318 (1992)

4 Landgren S, Aasly J, Backstorm T, Dubrovsky B and Danielsson $\mathrm{E}$ : The effect of progesterone and its metabolites on the interictal epileptiform discharge in the cat's cerebral cortex. Acta Physiol Scand 131, 33-42 (1987)

5 Belelli D, Bolger MB and Gee KW: Anticonvulsant profile of the progesterone metabolite $5 \alpha$-pregnan-3 $\alpha$-ol-20-one. Eur J Pharmacol 166, 325-329 (1989)

6 Majewska MD, Mienville JM and Vicini S: Neurosteroid pregnenolone sulfate antagonizes electrophysiological responses to GABA in neurons. Neurosci Lett 90, 279-284 (1988)

7 Majewska MD, Demirgoren S, Spivak CE and London ED: The neurosteroid dehydroepiandrosterone sulfate is an antagonist of the GABA $_{\mathrm{A}}$ receptor. Brain Res 526, 143-146 (1990)

8 Tsujiyama S, Ujihara $\mathrm{H}$, Ishihara $\mathrm{K}$ and Sasa M: Potentiation of GABA-induced inhibition by 20 -hydroxyecdysone, a neurosteroid, in cultured rat cortical neurons. Jpn $\mathbf{J}$ Pharmacol 68, $133-136$ (1995)

9 Yamada J, Serikawa T, Ishiko J, Inui T, Takeda H, Kawai Y and Okaniwa A: Rats with congenital tremor and curled whiskers and hair. Exp Anim 34, 183-188 (1985)

10 Rhem S, Mehraein P, Anzil AP and Deerberg F: A new rat mutant with defective overhairs and spongy degeneration of the central nervous system; clinical pathological studies. Lab Anim Sci 32, 70-73 (1982)

11 Serikawa $\mathbf{T}$ and Yamada J: Epileptic seizures in rats homozygous for two mutations, zitter and tremor. J Hered 77, 441444 (1986)

12 Sasa M, Ohno Y, Ujihara H, Fujita Y, Yoshimura M, Takaori $\mathrm{S}$, Serikawa $\mathrm{T}$ and Yamada $\mathrm{J}$ : Effect of antiepileptic drugs on absence-like and tonic seizures in the spontaneously epileptic rat, a double mutant rat. Epilepsia 29, $505-513$ (1988)

13 Paxinos G and Watson C: The Rat Brain in Stereotaxic Coordinates. 2nd ed, Academic Press, Sydney (1986)

14 Sasa M, Ujihara H, Ishihara K, Ohno Y, Fujita Y, Yoshimura $M$, Nakamura J, Serikawa $T$, Yamada $T$ and Takaori $S$ : Responsiveness of the spontaneously epileptic rat (SER), a double mutant, to antiepileptic drugs. Adv Neurol Sci 33, 909-918 (1989) (Abstr in English) 